\title{
Evaluating RFID opportunity through process analysis
}

\author{
Davide Busato $^{\mathrm{a}}$, Marcello Fera ${ }^{\mathrm{b}}$, Raffaele Iannone ${ }^{\mathrm{c}}$, Vincenzo Mancini ${ }^{\mathrm{a}}$ \\ and Massimiliano M. Schiraldi ${ }^{\mathrm{a}, *}$ \\ a Department of Enterprise Engineering, “Tor Vergata” University of Rome, Italy \\ ${ }^{\mathrm{b}}$ Department of Aerospace and Mechanical Engineering, Second University of Naples, Italy \\ ${ }^{\mathrm{c}}$ Department of Industrial Engineering, University of Salerno, Italy
}

\begin{abstract}
Current literature agrees that one of the main results obtained by adopting RFID lies in an improved efficiency increase in material handling operations, especially regarding reductions in the time required to perform certain procedural steps. However, by evaluating only the advantages that can be easily quantified and definitely achieved may lead to limited results. This paper presents a business case of a large European Consumer Packaged Goods (FMCG) company in the cosmetics and beauty sector. Eleven processes in receiving, handling, storage and delivery procedures in one of the main distribution centres of the company were analysed and modelled using a detailed Business Process Modelling (BPM) approach. Since savings were evaluated only in terms of the reduction of resources used - achieved through process acceleration - despite the company dealing in huge volumes of high-margin products, the feasibility study turned out to be negative. Thus, the paper concludes with a brief discussion of how companies should take on this challenge if process timing benefits are insufficient. The detailed process analysis reported in this paper may be useful for operation practitioners or any manufacturing company or distribution centre about to start an as-is versus to-be comparison of their material handling procedures for RFID implementation.

Keywords: RFID project, process streamlining, process analysis, business process modelling, material management, fast movers consumer goods
\end{abstract}

\section{Introduction}

In general, the advantages of using RFID in logistics or supply chain management have already been acknowledged (Vecchi, \& Brennan, 2010; Attaran, 2010; Hinkka, 2012; Loebbecke, 2005; Sameer et al., 2009; Holzer, 2009; Sabbaghi, \& Vaidyanathan, 2008). Literature agrees that the most important applications of this technology are in production/inventory systems (Chowa, 2006; Nambiar A, N., 2009; Hardgrave et al., 2009): picking, stacking, shipping and other material handling operations can be performed more efficiently, accurately and automatically, with potentially significant time savings. Inventory levels can be checked in real-time and the correct replenishment strategy is automatically achieved (Lee et al., 2011); visibility

\footnotetext{
*Corresponding author: Massimiliano M. Schiraldi, Department of Enterprise Engineering, "Tor Vergata" University of Rome, Italy. E-mail: schiraldi@uniroma2.it.
} 
of warehouse operations and workers' productivity are critical issues (Poon et al., 2009; Battista et al., 2013; Fumi et al., 2013) that can be improved. On top of this, intelligent information systems which incorporate route optimizing programmable models, as well as automatic data identification based on RFID to assist logistics service providers are now available (Werner et al., 2010; Wei, \& Leung, 2011; Escribano et al., 2012).

However, in a survey compiled by the Warehousing Education and Research Council (WERC) members, aimed at defining what challenges they were facing in RFID implementation, it was clear that many companies were not considering RFID adoption at all (Vijayaraman, \& Osyk, 2006). Despite its huge flexibility (Ferrer et al., 2010, 2011; Zhu et al., 2012), several RFID project failures have been recorded due to the incorrect inclusion of key success factors (Ngai et al., 2012) and many decisionmakers still considered RFID technology to be useful only to large organizations, due to their capability for exploiting scale economies. Despite us being far from a general representation of the ideal RFID adoption process, the possible obstacles that we may come across in an implementation project have been thoroughly analysed together with potential solutions (Wu et al., 2006); specifically, attempts have been made to establish the optimal configuration for RFID in warehouse management (Pacciarelli et al., 2011).

The most common approach to perform an economic evaluation of the RFID implementation opportunity is to develop a feasibility study computing some profitability indices such as Return on Investiment (ROI) and Net Present Value (NPV) (Simeonov, 2004; Bottani et al., 2008; Bertolini et al., 2010). However, these methods require the computation of the Discounted Cash Flow (DCF), which, in turn, requires a precise economic estimate of all the benefits derived from the introduction of RFID technology over a timeframe of at least five years. Here, considerations of fixed (infrastructure) costs and variable (tag) costs associated with implementing and using the system are compared to the potential economic advantages (Riggins, \& Hardgrave, 2007). Some benefits, however, are not easy to estimate and correlate with the RFID introduction, e.g. increase in quality of work. Thus, a great part of feasibility studies focus on savings that can be easily quantified and definitely achieved.

Traditional accounting systems focus on the evaluation of tangible assets, ignoring the increased value given by intangible assets to business performance (Cricelli et al., 2008; Greco et al., 2013). In most cases, especially in the manufacturing sector, the analysis primarily relies on tangible benefits related to efficiency increase, specifically to the reduction of resources used due to time savings, which is obtained by deleting certain manual steps in the material handling procedure in the inbound logistic processes. For instance, in an exhaustive study by Bottani et al. (2008), a panel of 11 major companies, namely 6 manufacturers and 5 distributors of FMCG, were considered to depict a representative supply chain in which RFID benefits could be quantitatively analysed. Results show that, in the most general case of tagging at pallet level, $90 \%$ of savings in "receiving" operations for the manufacturer were attained by reducing the amount of time required to perform certain procedural steps; 
in distribution centres, time reduction in "shipping" operations accounted for $80 \%$ of total savings and for $90 \%$ of "inventory management" operations in retail stores. These results may convince management to concentrate mainly on savings in terms of time reductions. However, focusing the analysis on these factors alone may cause the business case ROI to become negative (De Souza et al., 2011).

This paper presents a business case of a large European Consumer Packaged Goods (FMCG) company evaluating RFID introduction into one of its distribution centres. The company, operating in the cosmetics and beauty industry, was urged to test RFID profitability by a big retailer company, which forced its suppliers to deliver pallets and delivery cases using RFID tags. The company's management considered this requirement as a good opportunity to start a streamlining process study. The analysis was carried out with a detailed Business Process Modelling (BPM) approach, and the savings were evaluated only in terms of the reduction of resources used, achieved through process acceleration. As a result, despite the company dealing in huge volumes of high-margin cosmetic and beauty products - which seemed an ideal context in which to adopt RFID tagging - the feasibility study turned out to be negative. On top of the remarks about the opportunity of evaluating the RFID project only through time savings, the detailed process analysis reported in this paper may be useful for operation practitioners or any manufacturing company or distribution centre which is about to start an as-is versus to-be comparison of their material handling procedures for RFID implementation. Even if these diagrams refer to a specific industrial case and are not intended to represent ideal procedures, they may be used both as an example of the detail level at which a process analysis should be performed, and as a reference to check whether time savings can be achieved in certain steps of the inbound logistic procedures.

\section{Process modelling and analysis approach}

As reported by several authors (Tzeng et al., 2008; Fera et al., 2013), the development of an RFID project is a complex task, involving not only "buying hardware and software", but also the reengineering of internal processes and provision of a new definition of procedures and activities for RFID implementation, according to the business process re-engineering (BPR) approach (Hammer, \& Champy, 1993; Bevilacqua et al., 2011). The traditional methodology is based on business process analysis as a tool to map, document and understand processes, and includes, among others, the following steps (Bottani et al., 2008, 2009; Bottani, Ferretti et al., 2009):

1. documenting the current process;

2. defining its future state based on RFID implementation;

3. estimating value and productivity performance metrics of RFID processes.

The feasibility assessment is generally performed through the implementation of three sub-steps, namely "as-is analysis", "to-be re-engineering" and a final costs and savings assessment. The as-is analysis is a systematic data collection phase, concern- 
ing relevant processes, operations and activities currently performed and targeted for study within the RFID project. Here, attention is mainly paid to the time necessary for the completion of every single step of the process. This time analysis is performed using real time measurements. Sometimes only the more promisingly profitable logistic processes are considered, in order to obtain an initial idea of the real advantages that this technology may bring. Starting from the as-is analysis, the feasibility assessment should provide to-be re-engineering scenarios, hypothesising a new definition of procedures, activities and operations that perform the same processes adopting RFID technology (Bottani, Ferretti et al., 2009). With the introduction of the new technology, some of the steps in each single process may take less time or may even no longer be necessary. On the contrary, sometimes the RFID introduction may create some new, time-consuming steps. By analysing the gap between costs and savings resulting from the implementation of to-be re-engineered processes, the relevant economic figures can be derived.

BPM is a consolidated approach for representing processes by providing a base for measuring their performances analytically. The modelling must be closely related to performance metrics (Han et al., 2009), thus the choice of the appropriate detail level in representing the process diagram is critical. It is crucial to adopt a notation that can be easily understood by all business users, from the business analysts that create the initial processes drafts, to the technical developers responsible for the implementation of the technology that will support those processes and, finally, to the people who manage and monitor those processes. The BPMN - Business Process Model and Notation (OMG, 2011) seems to be perfectly suited to represent business processes in order to perform BPR analyses that support RFID project evaluations.

\section{A case in the FMCG industry}

The receiving, handling, storage and delivery processes carried out in a $200,000+\mathrm{m}^{2}$ distribution centre of a primary European company in the cosmetics and beauty sector have been analysed. The company's name, the project details and some specific process data could not be reported in the paper due to confidentiality reasons.

The estimate of the time savings resulting from the introduction of RFID was performed using a detailed process analysis. As-is diagrams were compared with to-be diagrams, which represent the case of RFID being used; steps that need to be added, due to the new technology introduction, were identified and highlighted (dotted contour line in the following charts), as well as those that can be eliminated (shaded boxes). The time saving achievable through RFID introduction in each step of these processes was estimated by a team of internal analysts, who measured the time duration of the as-is process and simulated the procedure assuming the presence of RFID smart labels.

Every step where pallets and/or cases were moved ("touch-points") and each identification phase where a manual/automatic data entry occurred were analysed (Fig. 1). 


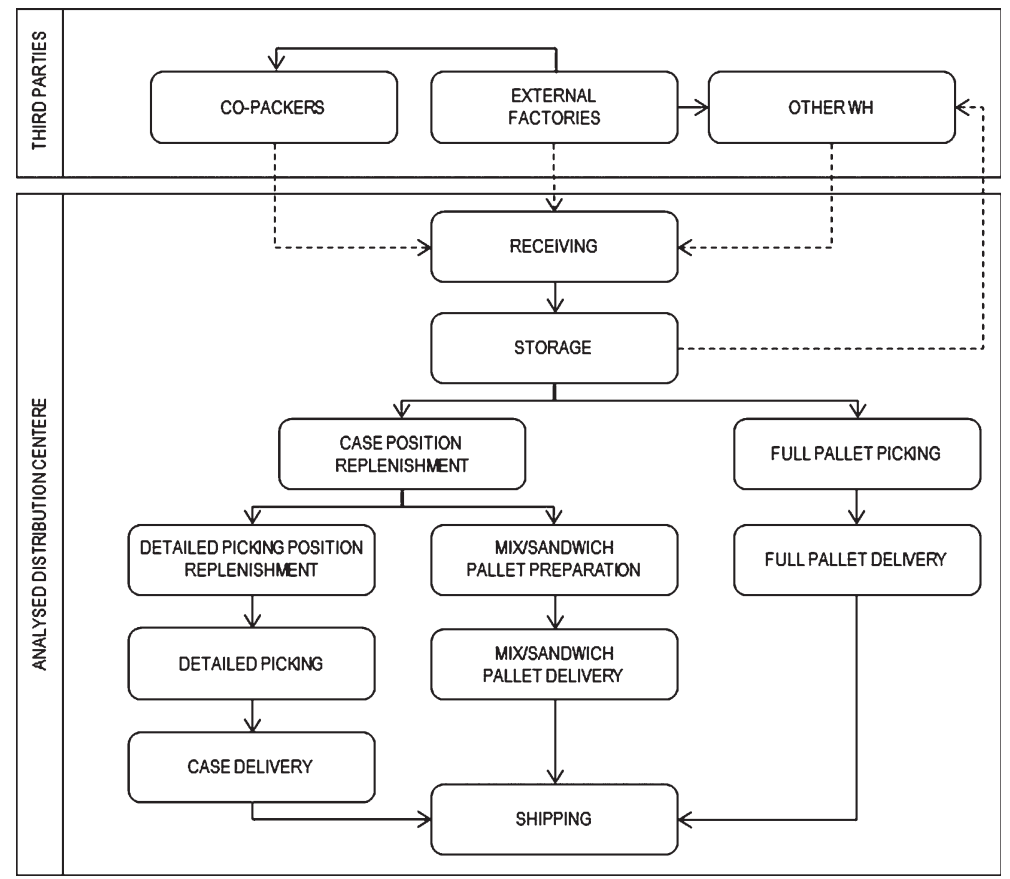

Fig. 1. Flows in the analysed distribution center.

The sequence of these steps was greatly influenced by the company's Enterprise Resource Planning (ERP) system procedures. In this specific case, as in most FMCG corporations, the ERP manages material handling and storage operations using two different modules: the warehouse management module (WM), which concerns storage and operations that include the movement of items inside the warehouse by implementing slot-locating capabilities, and the material management module (MM), which manages the handling process before the shipment phase. Only goods recorded as "booked" in the MM can be invoiced and sold to the customer. Conversely, goods entering the warehouse need to be fetched by the WM module in order to proceed with the physical storage operation.

Eleven processes were analysed and are listed below:

1. receiving and storage process for goods coming from external factories;

2. receiving and storage process for goods coming from other warehouses;

3. receiving and storage process for goods coming from co-packers;

4. process for full pallet picking (transaction from WM to MM);

5. process for the shipping of goods to the external warehouse (transaction from internal WM to external WM);

6. process for relocation operations (transaction within $\mathrm{MM}$ ); 
7. process for replenishment of case positions (transaction from WM to MM);

8. process for re-storage operations (transaction from MM to WM);

9. process for full pallet shipping;

10. process for mix-sandwich pallet shipping;

11. process for delivery case shipping.

The large array of symbols and icons in the BPMN 2.0 standard seemed excessively sophisticated to represent the company's processes. Furthermore, in order to avoid the company having to implement BPMN 2.0 training, only the simpler symbols were used.

\section{Process diagrams and analysis}

\subsection{Receiving of goods and storage}

Receiving and storage procedures differ in the case of goods coming from other warehouses, external factories or co-packers, mainly because some information might already be integrated into the company's ERP, and due to the possible need for checking the content of incoming pallets or printing barcode labels. Generally speaking, the receiving process starts when the company receives a delivery notice with information regarding the type and quantity of incoming goods and trucks that need to be unloaded.

Diagrams showing these processes are depicted in Figs. 2, 3 and 4 below. It is possible to see that many steps could be eliminated through the introduction of RFID technology. This was clear from the beginning of the project, and it was the belief of the company's management. Note that all items are batched in cases, which are consolidated in pallets. The latter are the logistic units (Warehouse Unit, WU), identified through the 18-digit Serial Shipping Container Code (SSCC). In the as-is scenario the SSCC is encoded in a barcode, while in the to-be scenario a smart label with barcode and RFID is used in order to store the SSCC and the Electronic Product Code (EPC).

In the to-be process, the option of using forklifts with RFID readers was considered to save additional time by avoiding manual scans by warehouse employees. Results of the time difference computation between the as-is and to-be processes, for each of the three cases, are shown in Tables 1,2 and 3. Only the process steps with significant time variations are listed. Values refer to the handling of one single unit (pallet, in these cases) in each process.

It is possible to see that significant time savings may result from the introduction of RFID in these three processes. Time increases highlighted by $\left(^{*}\right)$ in the above tables refer to the printing of new labels, when problems are detected in terms of discrepancies between the delivery note and real delivery data. Since discrepancies occur only rarely, the time increase was estimated as the ratio between the average time taken to print the new label (10") and the frequency of discrepancies, estimated using the reported quality rates. 


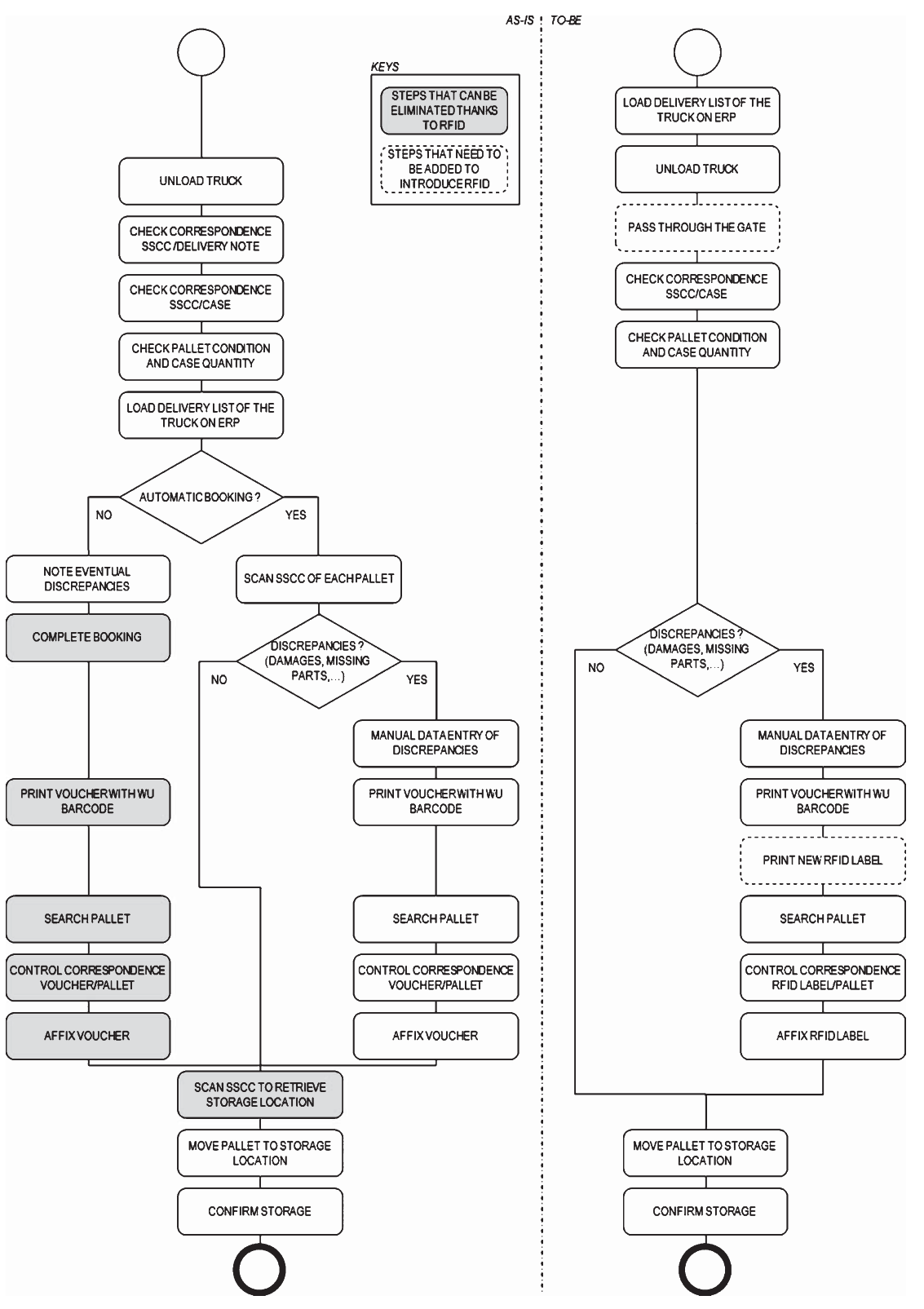

Fig. 2. Receiving of goods from other warehouses and storage process. 


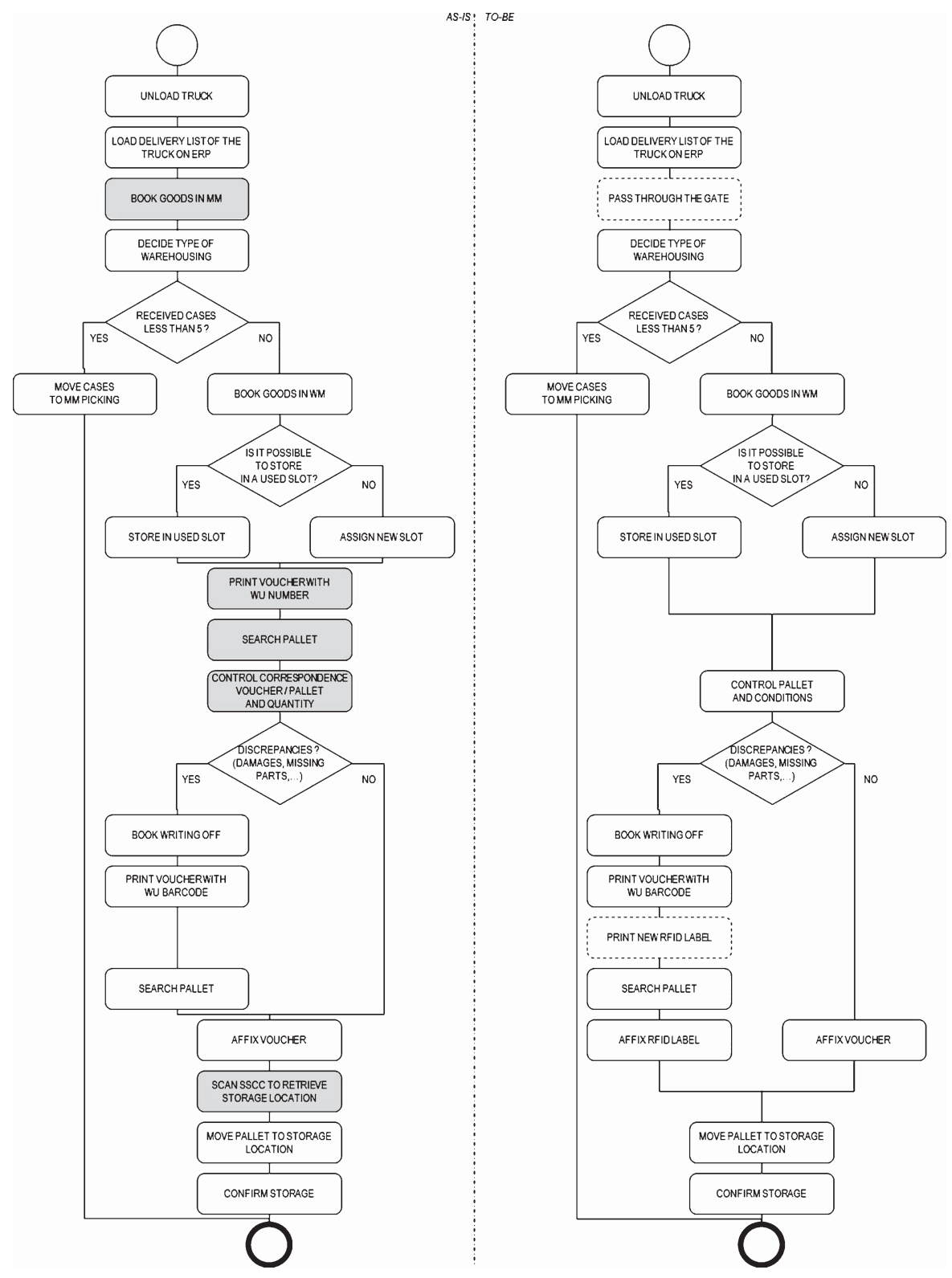

Fig. 3. Receiving of goods from external factories and storage process. 


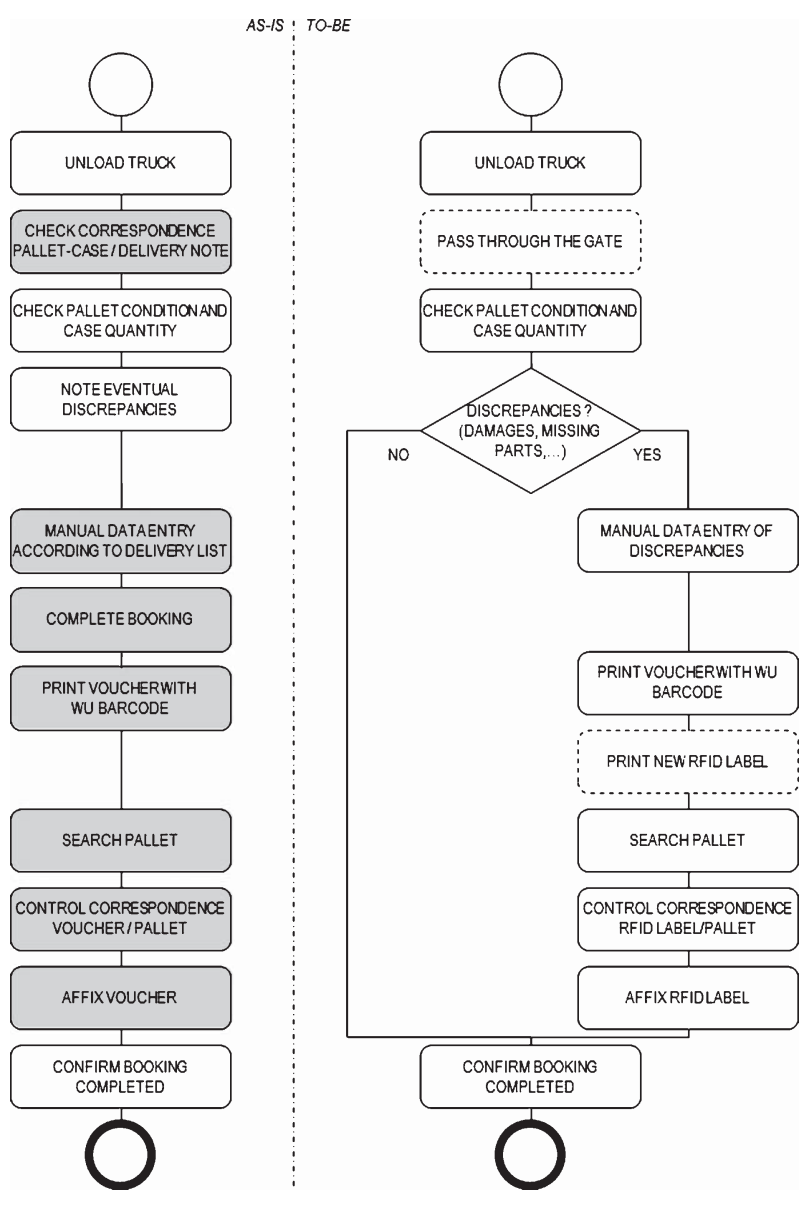

Fig. 4. Receiving of goods from co-packers and storage process.

Table 1

Time savings for receiving of goods from external warehouses

Process step

Time saved [s]

Check correspondence SSCC/Delivery note

9.50

Book pallets in the office

7.30

Affix bar code on pallet

19.70

Print new RFID tag for pallets with problems $\left(^{*}\right)$

$-0.05$

Scan SSCC to get storage position

10.50

Total time savings 
Table 2

Time savings for receiving of goods from external factories

\begin{tabular}{lc}
\hline Process step & Time saved [s] \\
\hline Check correspondence SSCC/Delivery note & 19.20 \\
Book pallets in the office & 5.60 \\
Affix bar code on pallet & 26.70 \\
Print new RFID tag for pallets with problems $\left(^{*}\right)$ & -0.60 \\
Scan SSCC to get storage position & 10.50 \\
Total time savings & 61.40 \\
\hline
\end{tabular}

Table 3

Time savings for receiving of goods from co-packers

\begin{tabular}{lc}
\hline Process step & Time saved [s] \\
\hline Check correspondence Pallet/Delivery note & 19.20 \\
Book pallets in the office & 20.60 \\
Affix bar code on pallet & 26.70 \\
Print new RFID tag for pallets with problems $\left(^{*}\right)$ & -0.30 \\
Scan SSCC to get storage position & 10.50 \\
Total time savings & 76.70 \\
\hline
\end{tabular}

\subsection{Full pallet picking}

In picking operations (Fig. 5), transactions from WM to MM need to be performed. When picking an entire pallet, the time needed to manually scan its WU bar code and to retrieve the voucher is replaced by an EPC read operation that is automatically performed by the RFID forklift readers as the pallet is picked. Time savings are reported in Table 4.

\subsection{Goods shipping to other warehouses}

Similarly to what happens in full picking operations, RFID can reduce the time needed to scan and remove the voucher in goods shipping to external warehouses (Fig. 6). In this specific case, since it is not a selling procedure, the transaction is recorded from the internal WM to an external WM module of the Company's ERP. Time savings are reported in Table 5.

\subsection{Relocation operations}

Pallets are handled internally within the warehouse (Fig. 7) for relocation purposes and thus the transaction is recorded only within the WM module of the ERP: here the use of RFID can achieve time savings only during the identification phase before the storage positions are changed. Time savings are reported in Table 6. 


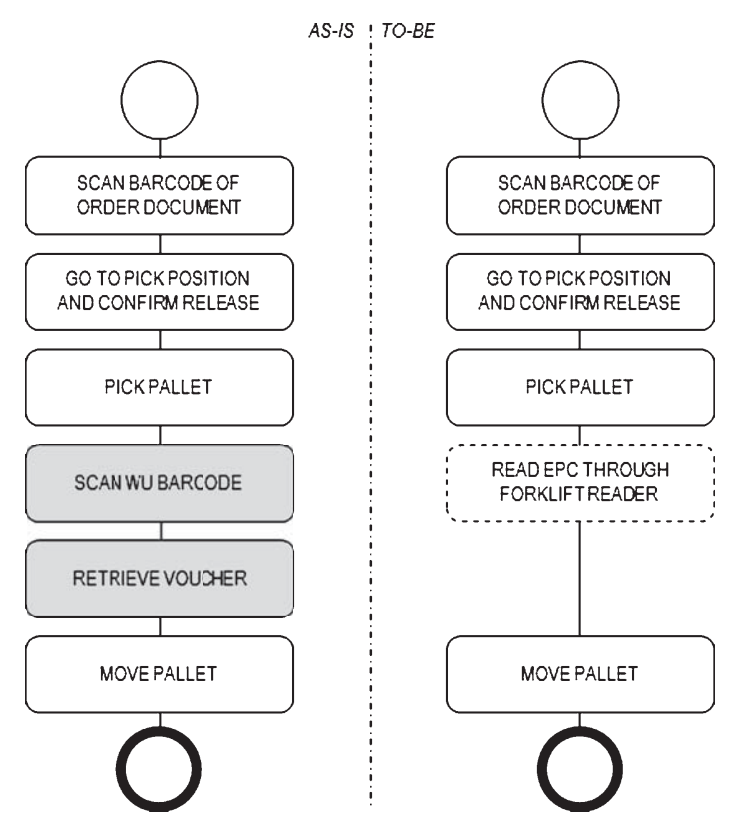

Fig. 5. Processes for full pallet picking.

Table 4

Time savings in full pallet picking process

\begin{tabular}{lc}
\hline Process step & Time saved [s] \\
\hline Scan WU bar code & 09.20 \\
Retrieve voucher & 15.80 \\
Total time savings & 25.00 \\
\hline
\end{tabular}

\subsection{Replenishment of case positions}

Here (Fig. 8), cases are picked and brought to the positions where they are assorted in mix. Pallets must be unwrapped, since they do not need to be shipped, and thus the smart label is lost. A transaction is recorded from the WM to the MM module. Time savings are reported in Table 7.

\subsection{Re-storage operations}

This process (Fig. 9) is related to the movement of products from material management back to the warehouse ("back-to-stock"). It is necessary to print a new WU voucher in order to again ensure a coherent identification of the pallet. In this case, RFID technology does not grant any time saving, since the RF tag printing 


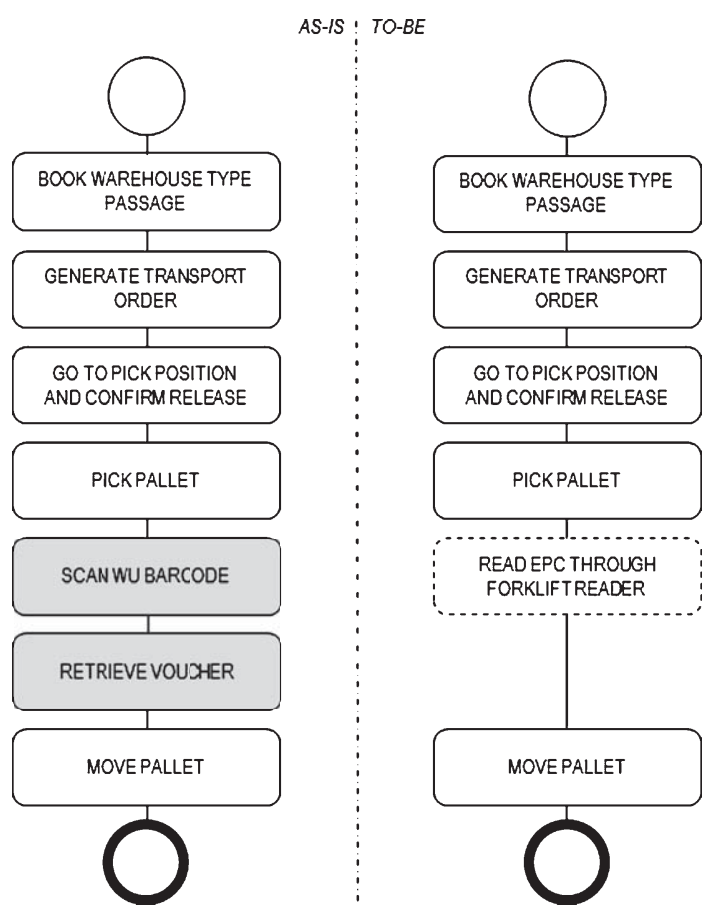

Fig. 6. Processes for goods shipping to other warehouses.

Table 5

Time savings in goods shipping to other warehouse

\begin{tabular}{lc}
\hline Process step & Time saved [s] \\
\hline Scan WU bar code & 09.20 \\
Take voucher & 15.80 \\
Total time savings & 25.00 \\
\hline
\end{tabular}

and affixing operations take almost the same time as the bar-code device setting and scanning activities, as it is possible to see in Table 8 .

\subsection{Goods shipping}

With the RFID-enabled process for managing mix and sandwich pallet shipping (Fig. 10), as well as for delivery cases (Fig. 11), new steps are needed: the warehouse employee uses a scanner connected to a portable RFID printer. Full pallets (Fig. 12) already have a smart label with an SSCC code, while for mix and sandwich pallets, as well as cases, a new label must be printed and affixed. All goods are ready to be shipped, since they were already recorded in the MM module during the picking 


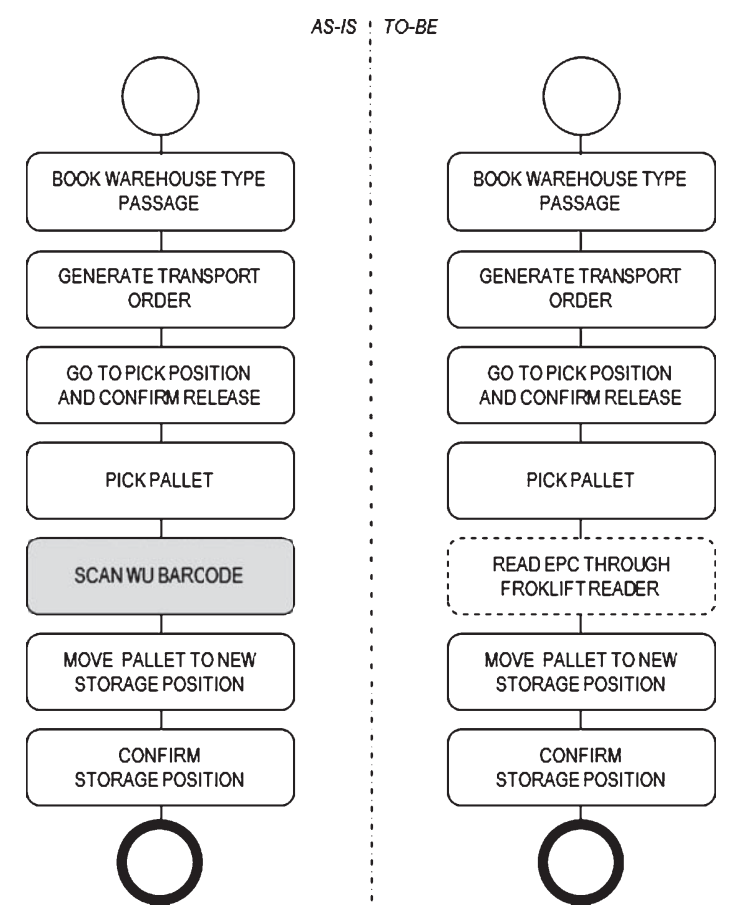

Fig. 7. Processes in relocation operations.

Table 6

Time savings in relocation operations

\begin{tabular}{lc}
\hline Process step & Time saved [s] \\
\hline Scan SSCC to get new storage position & \\
Choose receiving function & 4.50 \\
Scan bar code & 5.50 \\
Total time savings & 10.00 \\
\hline
\end{tabular}

phase. Some problems are encountered only when defective labels are printed (during the first tests, the defective label rate was $6 \%$ - in these cases the printing operation must be repeated) and when the input label roll needs to be replaced (one roll contains 1000 labels, thus roll substitution was not infrequent). Time savings are reported in Table 9.

\section{Cost-benefits analysis}

In order to quantify the total time savings, the number of handled units in each process was considered. This data is shown in Table 10. 


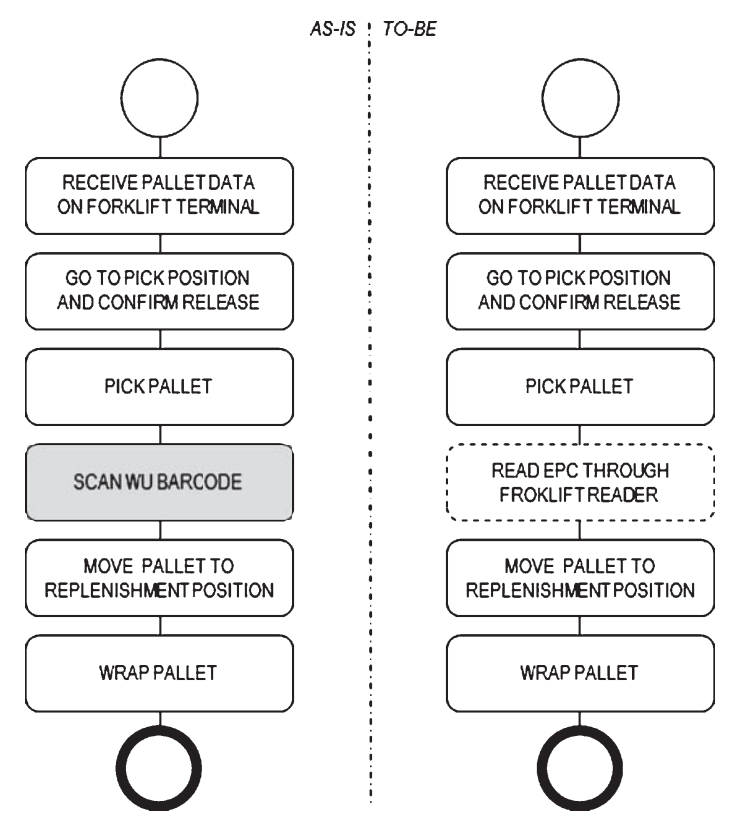

Fig. 8. Processes in replenishment of cases positions.

Table 7

Time savings in replenishment of cases positions

\begin{tabular}{lr}
\hline Process step & Time saved [s] \\
\hline Scan SSCC to get new storage position & \\
Choose receiving function & 4.50 \\
Scan bar code & 5.50 \\
Total time savings & 10.00 \\
\hline
\end{tabular}

Considering an average hourly cost of $17.40 € /$ hour per employee, estimated from internal reports analysis, a rough calculation of the economic value of time savings due to RFID introduction in the analysed processes give approximately $22.9 \mathrm{~K} €$ in the examined year, as shown in Table 11. In each process, time savings were multiplied by the number of handled units and by the aforementioned average cost of employees.

It is important to note that it is often unrealistic to estimate cost savings through a mere computation of process time reduction: for instance, underutilising an employee does not mean saving part of his salary. However, in this specific case, these problems were overcome by the negative results of the economic analysis, which are explained in the following paragraphs.

The advantages of RFID introduction must be compared with the cost related to the new system implementation and management. In order to perform a complete 


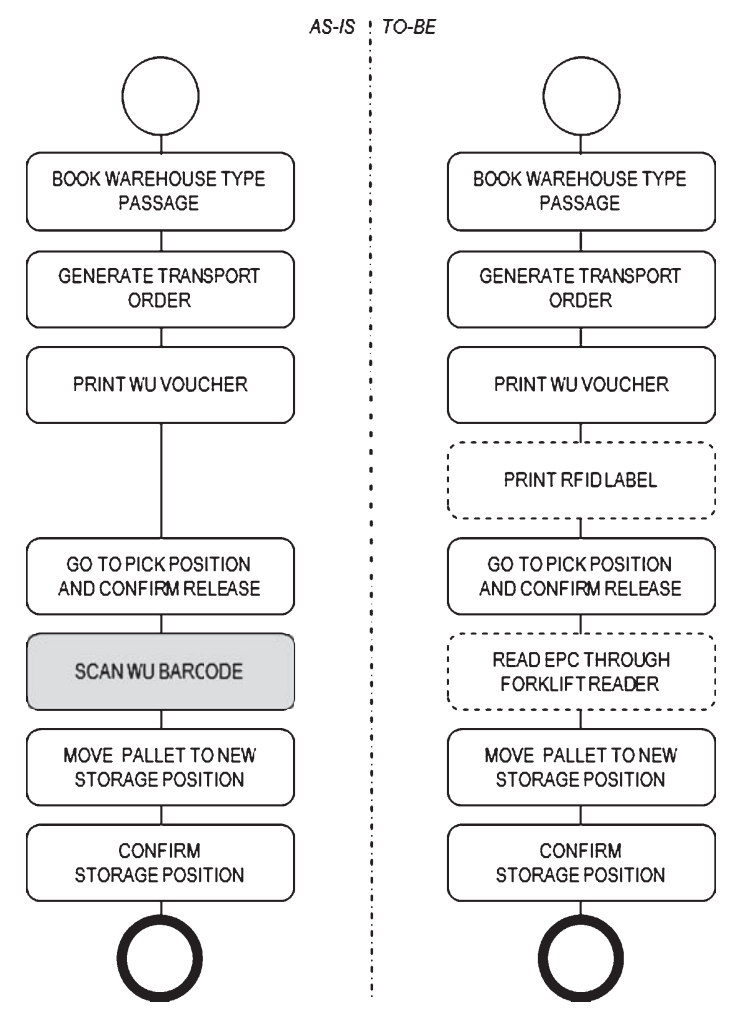

Fig. 9. Processes in re-storage operations.

calculation of the economic feasibility of RFID adoption, a detailed analysis of each cost entry related to the project is needed. As usual, costs can be divided into capitalized and operational expenditures. Capitalized expenses include hardware (readers, gates, printers, control and data-storage systems etc.) and software (middleware, legacy system interface software, application integration, etc.). Operational expenditures include hardware and software maintenance and software licenses, training, subscription to EPCGlobal and, most importantly, label cost. A comprehensive list of cost entries related to RFID implementation can be found in Bottani and Rizzi, 2008. There are also a few more details to consider:

- data storage capacity is needed to store a log of item movements and information (EPC code, date, location etc.). It is important to note that in modern distribution systems, for each byte of stored data, roughly 3-3.5 bytes of storage space are needed (databases are typically cloned and each one is associated with a compressed backup); thus to save $1 \mathrm{~GB} /$ year over a 10 -year horizon implies the need for 30-35 GB of free storage space; 
Table 8

Time savings in re-storage operations

\begin{tabular}{lc}
\hline Process step & Time saved [s] \\
\hline Scan WU to get new storage position & \\
Choose receiving function & 4.50 \\
Scan bar code & 5.50 \\
Print new RFID label & -10.00 \\
Total time savings & - \\
\hline
\end{tabular}

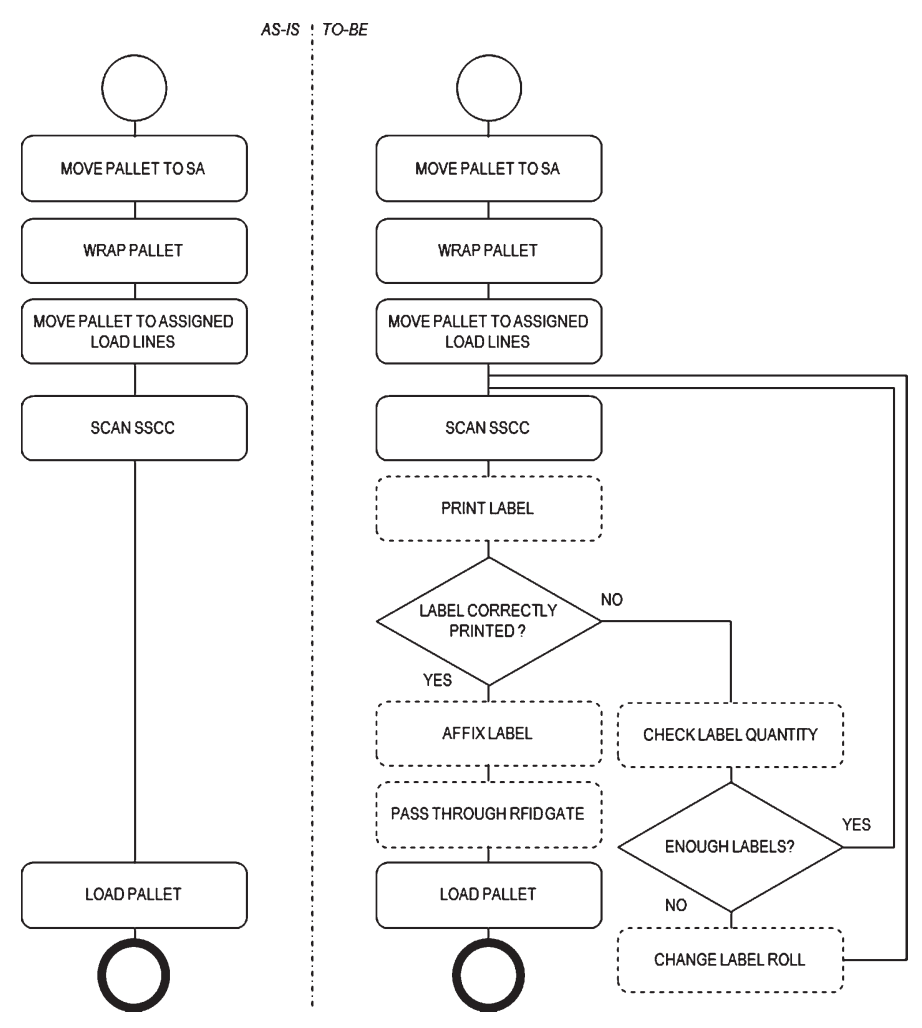

Fig. 10. Processes in full pallet shipping.

- maintenance costs generally vary between $15 \%$ and $25 \%$ of the initial investment cost. In order to take advantage of cost improvement opportunities, a 5\% reduction of this percentage must be applied each year (Mancini et al., 2012); redundant hardware should be taken into consideration, especially when dealing with portable devices (handheld readers, portable printers, etc.).

- the annual subscription to EPC Global is paid - in the country in which the company is headquartered - based on annual turnover. EPC Global is an organization set up to achieve worldwide adoption and standardization of EPC technology; the 


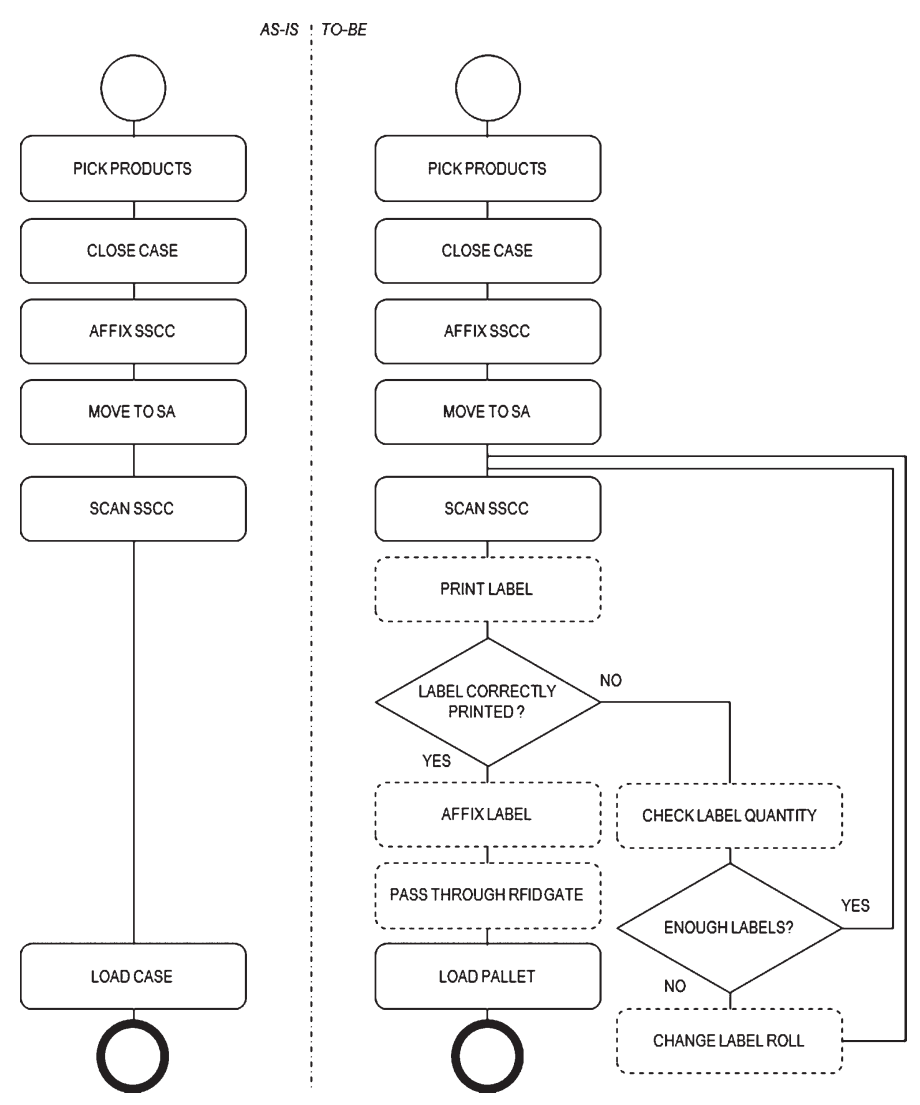

Fig. 11. Process in mix-sandwich pallet shipping.

annual subscription covers full access to the EPC global network, standards, EPC Global working groups and the Object Naming Service (ONS), which allows the use of legacy 64-bit tags in an EPC global compliant trial. Additional fees can be requested for single divisions or subsidiaries.

Tag or label costs obviously depend on the total number of handled items which, in turn, depends on the management's choice to tag either at pallet, case or item level. It is essential to distinguish between a tag and a label: a tag is the core component where data is saved, composed of antenna and a memory unit; usually, it is not possible to affix a tag directly to the item, and the tag must first be printed on adhesive paper. On a paper label, a human readable code and a barcode which backs up the RFID data - for instance the Serial Shipping Container Code (SSCC) and the Electronic Product Code (EPC) code - may be printed. In this way a "smart label" is created. While a tag can cost $0.10-0.15 €$, the cost of a smart label may increase up to 0.40 


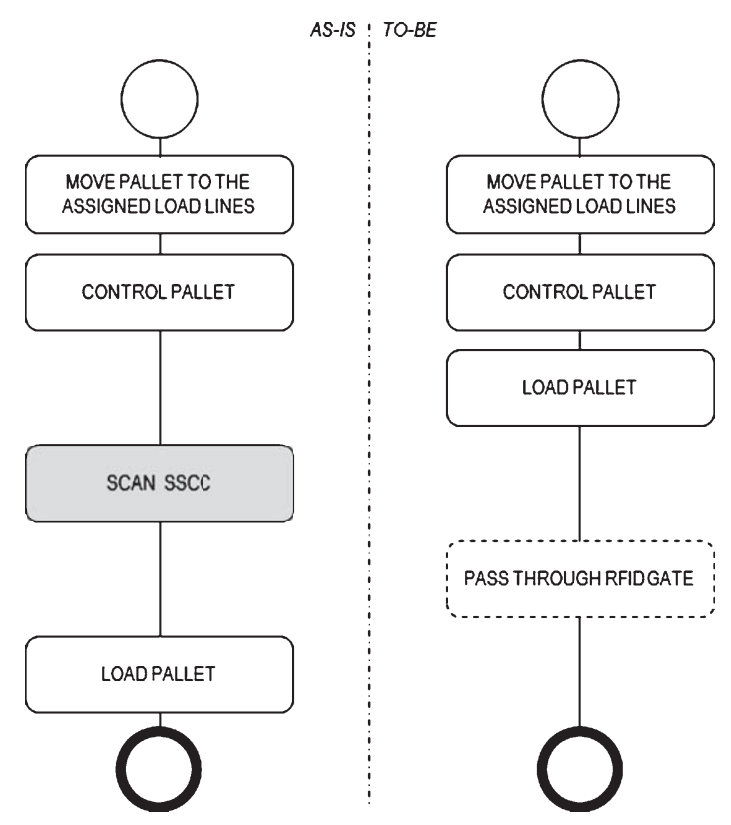

Fig. 12. Processes for case shipping.

Table 9

Time savings in goods shipping

\begin{tabular}{lc}
\hline Full pallet & \\
\hline Process step & Time saved [s] \\
\hline Scan SSCC & 7.00 \\
Total time savings & 7.00 \\
Mix/sandwich pallets and cases & \\
\hline Process step & Time saved [s] \\
\hline Scan SSCC & -4.20 \\
Retrieve label & -5.30 \\
Affix label & -7.50 \\
Change roll & -0.20 \\
Total time savings & -18.20 \\
\hline
\end{tabular}

$€$, including printing. In this specific case, EPC Class 1 Gen $2868 \mathrm{MHz}$ smart labels were considered, at a price of $0.25 €$ each.

Smart labels need to be added to all pallets in the receiving processes and in all shipments of mix/sandwich pallets and cases (full pallet shipping would benefit from having the labels affixed during the receiving process). As shown in Table 12, the total label cost clearly exceeded the estimated savings. 
Table 10

Handled pallet per process in the analysed year

\begin{tabular}{lc}
\hline Process & Units (x1000) \\
\hline Receiving (all processes) & 83.0 \\
Receiving from external factories & 60.7 \\
Receiving from other warehouses & 6.6 \\
Receiving from co-packers & 15.7 \\
Full pallet picking & 41.7 \\
Shipping to external warehouses & 26.5 \\
Relocation operations & 15.4 \\
Replenishment of case positions & 20.3 \\
Re-storage operations & 18.3 \\
Shipping (all processes) & 166.8 \\
Full pallets shipping & 41.7 \\
Mix-sandwich pallet shipping & 42.7 \\
Delivery case shipping & 82.4 \\
\hline
\end{tabular}

Table 11

Time and economic savings for each process

\begin{tabular}{lcc}
\hline Process & Saved time $[\mathrm{h}]$ & Savings per process [€] \\
\hline Receiving (all processes) & $1^{\prime} 237$ & $21^{\prime} 536$ \\
Full pallet picking & 290 & $5^{\prime} 045$ \\
Shipping to external companies & 184 & $3^{\prime} 196$ \\
Re-storage operations & 43 & 743 \\
Replenishment of case positions & 56 & 975 \\
Transaction from MM to WM & 0 & 300 \\
Shipping (all processes) & -552 & $-9^{\prime} 613$ \\
Total estimated savings & & $22^{\prime} 863$ \\
\hline
\end{tabular}

It is noticeable that more than $60 \%$ of the label cost is due to the shipment phase and this is because handling mix/sandwich pallets and delivery cases requires the company to reprint additional labels, thus wasting time and money.

For the sake of completeness, the main cost entries of the investment are summarized in Table 13 below:

Adopting an amortization period of 5 years for hardware costs and of 3 years for software costs, the project would not turn profitable even assuming zero-cost labels. Clearly, the handled volume growth rate could not affect the analysis results, since the savings would increase as well as the cost. Thus, the RFID implementation project was cancelled from the company's plan.

\section{Criticism of the presented approach}

Despite its precision and high level of detail, the analysis described showed a limited view on the part of the company analysts, who only examined the timing benefits of 
Table 12

\begin{tabular}{lcc}
\hline Process & Units $(\mathrm{x} 1000)$ & Labels cost [€] \\
\hline Receiving (all processes) & 83.0 & $20^{\prime} 750$ \\
Mix/Sandwich pallet shipments & 42.7 & $10^{\prime} 675$ \\
Case shipments & 82.4 & $20^{\prime} 600$ \\
Total labels cost & & $52^{\prime} 025$ \\
\hline Economic evaluation in the first year & & Value [€] \\
\hline Total labels cost & & $-52^{\prime} 025$ \\
Total estimated savings & & $22^{\prime} 863$ \\
Economic result & & $-29^{\prime} 162$ \\
\hline
\end{tabular}

Table 13

Fixed asset costs

\begin{tabular}{lc}
\hline Cost entry & Value [€] \\
\hline Hardware & $90^{\prime} 300$ \\
Gates & $44^{\prime} 300$ \\
Readers & $30^{\prime} 000$ \\
Printers & $16^{\prime} 000$ \\
Software & $35^{\prime} 200$ \\
Printing software & $4^{\prime} 200$ \\
Gates software & $8^{\prime} 600$ \\
System integration & $12^{\prime} 400$ \\
EPC integration & $10^{\prime} 000$ \\
Training & $1^{\prime} 000$ \\
Total system cost & $126^{\prime} 500$ \\
\hline
\end{tabular}

RFID. Analysing process times alone may very well be insufficient to justify the large costs associated with an RFID project of this size.

In more complete cost-benefit analyses related to RFID introduction, benefits are generally classified in the following categories (Mancini et al., 2012):

- benefits related to an increase in efficiency, i.e. resource productivity increase or process quality increase, with a consequent decrease in resource costs;

- benefits related to an increase in effectiveness, i.e. improvement in the critical-toquality levels or in customer satisfaction with a consequent increase in revenue;

- benefits related to improvements in data management, i.e. increase in quantity, quality and timeliness of information available to managers;

- benefits related to compliancy with possible legal requirements;

- benefits related to an improvement in the company image.

The approach presented only focused on a specific aspect relative to the first point. One may certainly agree that the economic return of improvements due to compliancy 
with possible legal requirements and company image improvements may be difficult to estimate. However, efficiency and effectiveness increases are tangible benefits that analysts should not neglect to take into account when assessing an RFID implementation, even if these benefits originate from several different aspects, which may not be as easy to evaluate as process time savings (Bardaki et al., 2010; Curtin et al., 2013).

For example, from a work force requirement point of view, on top of the process steps described in this paper, some other operations in a Distribution Centre may be accelerated thanks to RFID (Bottani, \& Rizzi, 2008). The following activities may not be included in the standard day-by-day procedures but in some industrial contexts may significantly absorb man-hours:

- checking operations and amending errors in handling operations;

- performing general and replenishment inventory counts;

- identifying items/cases/pallets location (Angeles, 2005);

- updating the information system.

Moreover, from a material management point of view, more benefits may result from the substantial reduction of stock level and product shrinkage:

- shrinkage encompasses products whose shelf life has expired due to incorrect application of FIFO (first-in first-out) or FEFO (first-expiring first-out) policies to inventory management (Bushnell, 2000);

- benefits of stock-out reduction have the potential to significantly impact the overall profitability of the implementation.

Bottani \& Rizzi in 2008 suggested a precise method to calculate the benefits of shrinkage and stock-out reduction for RFID implementation in Distribution Centres.

Other economical returns may come from improvements in data management: the availability of precise real-time data allows:

- improvements in forecasts (Asif, \& Mandviwalla, 2005);

- reduction of the overall supply chain inventory waste caused by the bullwhip effect (Alinean, 2006; Lapide, 2004);

- higher accuracy in the event of product recalls (Bottani, 2009);

- reduction of turnover losses due to counterfeiting, if RFID is used for item-level tagging to ensure product authenticity (Montanari, \& Rizzi, 2007).

Clearly, these last four improvement possibilities are harder to quantify when compared either to time-savings or to shrinkage/stock-out reduction. But this should not discourage the analysts from including them in the analysis.

For example, the adoption of RFID technology can also lead to a gain in competitive advantage with vendors/customers/3PL service providers, and this would help the company to maintain a technological leadership position. However, this is typically considered as a purely intangible benefit and, thus, it is often excluded from a preliminary economic assessment. On the contrary, forecasting errors, as well as 
counterfeiting losses and stock levels together with the risk associated to a product recall are, or should be, numerically quantified in most companies. Despite the fact that they may be considered indirect effects of RFID introduction, the related tangible benefits may be significant.

\section{Conclusions}

This paper offers the reader an interesting cue for evaluating the profitability analysis of an RFID project and a return of experience with a concrete measure of some practical economic advantages. We presented the results of process streamlining analysis and cost reduction opportunities related to the introduction of the RFID system into a distribution centre of a big Fast-Movers-Consumer-Goods (FMCG) company selling high-margin cosmetic and beauty products. Despite it appearing to be an ideal context for the adoption of RFID tagging, the feasibility study gave a negative result. This is due to the fact that the savings were evaluated only in terms of the reduction of resources used by process acceleration. Several papers show that, generally, savings from RFID introduction consisted mainly of shortening the time required to perform certain procedural steps. Thus, every inbound logistics process, from the receiving of goods to their shipping, was analysed with a detailed Business Process Modelling (BPM) approach, comparing the as-is material handling procedures with a to-be state resulting from RFID implementation. However, the cost of labels alone, on top of capitalized expenses, superseded the value of savings.

This negative result can be explained mainly by two reasons:

1) due to the presence of mix/sandwich pallet and delivery case shipping, a great number of the received pallets do not maintain their integrity, and so several units need to be labelled twice, both during the receiving and the shipment processes;

2) the economical evaluation was based only on resource reduction resulting from time savings. This limited view on the part of the company's analysts who did not examine the additional benefits of RFID introduction may explain the negative conclusion.

RFID may bring several improvements in quality, security, flexibility and customer service levels and, despite the fact that these are difficult to evaluate quantitatively, their omission can easily lead to a straightforward rejection of RFID before due consideration of the technology is made. Advantages in terms of quality improvements achieved during the receiving of goods and shipping procedures, increase in effectiveness of stock level controls, counterfeit security improvements of products and components, traceability opportunities for production batches and single products, and reduction of out-of-stock situations, are certainly critical issues that need to be translated into economic value in order to obtain a better evaluation of the implementation of this technology. 


\section{References}

Alinean. (2006). The ROI of RFID in the supply chain (White Paper). Retrieved February 2013, from http://www.alinean.com.

Angeles, R. (2005). RFID technology: Supply-chain applications and implementations issues. Information Systems Management, 22(1), 51-65.

Asif, Z., \& Mandiviwalla, M. (2005). Integrating the supply chain with RFID: A technical and business analysis. Communications of the Association for Information Systems, 15, 393-427.

Attaran, M. (2010). Strategic implications of RFID implementations in the retail industry supply chain. International Journal of RF Technologies: Research and Application, 2, 155-171.

Bardaki, C., Kourouthanassis, P., Pramataria, K. (2010) Exploring the deployment and adoption of RFIDenabled retail promotions management. International Journal of RF Technologies, Research and Application, 2, 91-115.

Battista, C., Fumi, A., Laura, L., \& Schiraldi, M.M. (2013). Multiproduct slot allocation heuristic to minimize storage space, International Journal of Retail \& Distribution Management (forthcoming).

Bertolini, M., Bottani, E., Rizzi, A., \& Volpi, A. (2010). The Benefits of RFID and EPC in the Supply Chain: Lessons from an Italian Pilot Study. The Internet of Things, Springer New York, 293302.

Bevilacqua, M., Ciarapica, F.E., \& Marchetti, B. (2011). Integration of BPR and RFId technology in a process industry: Spare parts warehouse management analysis. International Journal of RF Technologies: Research and Application, 2(2010/2011), 205-223.

Bottani, E. (2009). On the impact of RFID and EPC on traceability management: A mathematical model. International Journal of RF Technologies: Research and Applications, 1(2), 95-113.

Bottani, E., \& Rizzi, A. (2008). Economical assessment of the impact of RFID technology and EPC system on the fast-moving consumer goods supply chain. Int J Production Economics, 112, 548-569.

Bottani, E., Hardgrave, B.C., \& Volpi, A. (2009). A methodological approach to the development of RFID supply chain projects. International Journal of RF Technologies: Research and Applications, 1(2), 131-150.

Bottani, E., Ferretti, G., Montanari, R., \& Rizzi, A. (2009). The impact of RFID technology on logistics processes of the fashion industry supply chain. International Journal of RF Technologies: Research and Applications, 1(4), 225-252.

Bushnell, R. (2000). RFID's wide range of possibilities. Modern Materials Handling, 1(5), 37.

Chowa, H.K.H., Choya, K.L., Leea, W.B., \& Laub, K.C. (2006). Design of a RFID case-based resource management system for warehouse operations. Expert Systems with Applications, 30, 561-576.

Curtin, J.P., Gaffney, R.L., \& Riggins, F.J. (2013). Identifying business value using the RFID e-Valuation Framework. International Journal of RF Technologies: Research and Applications, 4 (2012/2013), 71-91.

Cricelli, L., \& Grimaldi, M. (2008). A dynamic view of knowledge and information: A stock and flow based methodology. International Journal of Management and Decision Making, Inderscience Publishers, United Kingdom, 9(6), 686-698.

De Souza, R., Goh, M., Sundarakani, B., Wai, W.T., Toh, K., \& Yong, W. (2011). Return on investment calculator for RFID ecosystem of high tech company. Computers in Industry, 62, 820-829.

Escribano, J.G., De Dios, J.J., Pastor, J.M., \& Garcia, A. (2012). Improvement in the tracking of special loads by using a three-level RFID system. International Journal of RF Technologies: Research and Applications, 3 (2011/2012), 181-199.

Fera, M., Iannone, R., Mancini, V., \& Schiraldi, M.M. (2013). Economical evaluation of RFID technology in production environment. International Journal of Engineering Business Management, 5(39), 1-13.

Ferrer, G., Dew, N., \& Apte, U. (2010). When is RFID right for your service? International Journal of Production Economics, 124, 414-425.

Ferrer, G., Heath, S.K., \& Dew, N. (2011). An RFID application in large job shop remanufacturing operations. International Journal of Production Economics, 133, 612-621. 
Fumi, A., Scarabotti, L., \& Schiraldi, M.M. (2013) The effect of slot-code optimization on travel times in common unit-load warehouses, Service \& Operations Management, 15(4), 507-527.

Hammer, M., \& Champy, C. (1993). Reengineering the corporation. New York: Harper Business.

Han, K.H., Kang, J.G., \& Song, M. (2009). Two-stage process analysis using the process-based performance measurement framework and business process simulation. Expert Systems with Applications, 36(3-2), 7080-7086.

Hardgrave, B.C., Aloysius, J., \& Goyal, S. (2009). Does RFID improve inventory accuracy? A preliminary analysis. International Journal of RF Technologies: Research and Applications, 1(1), 44-56.

Hinkka, V. (2012). Challenges for building RFID tracking systems across the whole supply chain. International Journal of RF Technologies: Research and Applications, 3 (2011/2012), 201-218.

Holzer, A. (2009). Enabling supply chain coordination with information sharing. MBA/MS Thesis, Massachusetts Institute of Technology, September 2009.

Greco, M., Cricelli, L., \& Grimaldi, M. (2013). A strategic management framework of tangible and intangible assets, European Management Journal, 31, 55-66.

Lapide, L. (2004). RFID: What's in it for the forecaster? Journal of Business Forecasting Methods \& Systems, 23(2), 16-19.

Lee, C.K.M., Ho, W., Ho, G.T.S., \& Lau, H.C.W. (2011). Design and development of logistics workflow systems for demand management with RFID. Expert Systems with Applications, 38, 5428-5437.

Loebbecke, C. (2005). RFID Technology and Applications in the Retail Supply Chain: The Early Metro Group Pilot, 18th Bled eConference, eIntegration in Action, Bled, Slovenia.

Montanari, R., \& Rizzi, A. (2007). A new challenge in the pharmaceutical supply chain. European Pharmaceutical Review, 2, 103-108.

Mancini, V., Pasquali, M., \& Schiraldi, M.M. (2012). Opportunities for using RFID in the aircraft production process. International Journal for RF Technologies: Research and Applications, 3 (2011/2012), 243-255.

Nambiar, A.N. (2009). RFID Technology: A Review of its Applications. Proceedings of the World Congress on Engineering and Computer Science 2009 Vol II, WCECS 2009, San Francisco, USA.

Ngai, E.W.T., Chau, D.C.K., Poon, J.K.L., Chan, A.Y.M., Chan, B.C.M., \& Wu, W.W.S. (2012). Implementing an RFID-based manufacturing process management system: Lessons learned and success factors. Journal of Engineering and Technology Management Journal of Engineering and Technology Management, 29, 112-130.

Object Management Group (2011). Business Process Model and Notation. Standard 2.0, January 2001. Retrived from http://www.omg.org/spec/BPMN/2.0

Pacciarelli, D., D’Ariano, A., \& Scotto, M. (2011). Applying RFID in warehouse operations of an Italian courier express company. NETNOMICS, Springer Netherlands, pp. 1-14.

Poon, T.C., Choy, K.L., Chow, H.K.H., Lau, H.C.W., Chan, F.T.S., \& Ho, K.C. (2009). A RFID case-based logistics resource management system for managing order-picking operations in warehouses. Expert Systems with Applications, 36, 8277-8301.

Riggins, F.J., \& Hardgrave, B. (2007). Implementation and usage of radio frequency identification (RFID). Paper presented at the 40th Annual Hawaii International Conference on System Sciences, Hawaii, HI, 2007.

Sameer, K., Erin, D., \& Aaron, D. (5). (2009). Reverse logistic process control measures for the pharmaceutical industry supply chain. International Journal of Productivity and Performance Management, $582,188$.

Sabbaghi, A., \& Vaidyanathan, G. (2008). Effectiveness and Efficiency of RFID technology in Supply Chain Management: Strategic values and Challenges. Journal of Theoretical and Applied ElectronicCommerce Research, 3(2), 71-81.

Tzeng, S.F., Wun-Hwa, C., \& Fan-Yun, P. (2008). Evaluating the business value of RFID: Evidence from five case studies. International Journal of Production Economics, 112(2), 601-613.

Simeonov, T.D. (2004). RFID: ROI Opportunities after the Sunk Cost. Massachusetts Institute of Technology. 
Vecchi, A., \& Brennan, L. (2010). RFID supply chain implementation challeges for short life products. International Journal for RF Technologies: Research and Applications, 2, 117-134.

Vijayaraman, B.S., \& Osyk B.A. (2006). An empirical study of RFID implementation in the warehousing industry, International Journal of Logistics Management, 17(1), 6-20.

Vlad, V., Graur, A., Turcu, C.E., \& Popa, C. (2009). Enhancing the flexibility of manufacturing systems using the RFID technology, Proceedings of the Workshops on Advanced Information Networking and Applications, pp. 630-635.

Wei, J., \& Leung, S.C.H. (2011). A simulation modelling and analysis for RFID-enabled mixed-product loading strategy for outbound logistics: A case study. Computers \& Industrial Engineering 61, 209-215.

Werner, K., Schill, A., \& Scheibe, J. (2010). Correlating distributed RFID-based event data for logistics process monitoring. International Journal of RF Technologies: Research and Application, 2, 53-71.

Wu, N.C., Nystrom, M.A., Lin, T.R., \& Yu, H.C. (2006) Challenges to global RFID adoption. Technovation, 26, 1317-1323.

Zhu, X., Mukhopadhyay, S.K., \& Kurata, H. (2012). A review of RFID technology and its managerial applications in different industries. Journal of Engineering and Technology Management, 29, 152-167. 